Pacific Journal of Mathematics

ON A PROBLEM OF HURWITZ 


\title{
ON A PROBLEM OF HURWITZ
}

\author{
NORMAN P. HERZBERG
}

A. Hurwitz proposed the problem of finding all the positive integers $\boldsymbol{z}, \boldsymbol{x}=\left(x_{1}, \cdots, x_{n}\right)$ satisfying the diophantine equation $x_{1}^{2}+\cdots+x_{n}^{2}=z \cdot x_{1}, \cdots, x_{n}$. This paper investigates the question of which values of $z$ can occur, using only the most elementary techniques. An algorithm is given for determining all permissible values of $(z, n)$ for all $n$ below a given bound. As an application it is established that the only possible values in the range $z \geqq(n+15) / 4$ are $z=n, z=(n+8) / 3$ when $n$ is odd, and $z=(n+15) / 4$. As another application the fifteen values of $n \leqq 131,020$ for which the only permissible value of $z$ is $n$ have been found.

2. The problem of finding all the integer solutions $z, \boldsymbol{x}=\left(x_{1}, \cdots\right.$, $x_{n}$ ) of the equation

$$
x_{1}^{2}+\cdots+x_{n}^{2}=z \cdot x_{1}, \cdots, x_{n}
$$

was raised by A. Hurwitz in [1]. In that paper he showed that for $n>z$ there are no solutions. This is an easy consequence of Theorem 1 (see §3) and will be replaced by the stronger result in Theorem 3. To keep this paper self-contained, let us recall the following facts from [1].

For $n=2$, the only solutions are $z=2, x_{1}=x_{2}$; for upon setting $x_{1}=d y_{1}, x_{2}=d y_{2}$ with $\left(y_{1}, y_{2}\right)=1, y_{1}^{2}+y_{2}^{2}=z y_{1} y_{2}$, and so $z=2, x_{1}=$ $x_{2}=d$.

If $z, x_{1}, \cdots, x_{j}, \cdots, x_{n}$ is a solution, then so is $z, x_{1}, \cdots, x_{j}^{\prime}, \cdots, x_{n}$ where $x_{j}^{\prime}$ satisfies

$$
x_{j}+x_{j}^{\prime}=z \prod_{i \neq j} x_{i} .
$$

The $n$ solutions derived in this way are called the neighbors of $\boldsymbol{z}, \boldsymbol{x}$. Define the height of a solution to be simply $x_{1}+\cdots+x_{n}$, and call a solution fundamental if its height is no greater than the height of any of its neighbors. If a solution is not fundamental, it has a neighbor of strictly smaller height, and since the heights are all positive integers, in a finite number of steps we arrive at a fundamental solution. So we see that it suffices to study fundamental solutions. Moreover, it obviously suffices to study solutions that satisfy

$$
x_{1} \geqq x_{2} \geqq \cdots \geqq x_{n} \geqq 1 .
$$

Also, as Hurwitz point out, it is easy to see that fundamental solutions 
satisfying (2) are characterized by

$$
2 x_{1} \leqq z \prod_{i=2}^{n} x_{1} .
$$

We now propose to study the system of Equations (1), (2), (3), and shall regard $n$ as well as $z$ and $x_{1}, \cdots, x_{n}$ as variables. By the first remark in this section we may also assume

$$
n \geqq 3 \text {. }
$$

3. In this section we state our basic theorem. First some notation.

The trivial solution of (1)-(4) is $x_{1}=\cdots=x_{n}=1, z=n$. Call a nontrivial solution of (1)-(4) a SOL. For any SOL, we define

$$
\chi(\boldsymbol{x})=\text { the largest index } i \text { for which } x_{i}>1 \text {. }
$$

Theorem 1. Let $n, z, \boldsymbol{x}$ be a SOL with $k=\chi(\boldsymbol{x})$. There is a chain of SOLs $n^{(i)}, z, \boldsymbol{x}^{(i)}, i=0, \cdots, t$ such that

(a) $\chi(\boldsymbol{x})=\chi\left(\boldsymbol{x}^{(i)}\right)$ for all $i$.

(b) If $z=1$ and $k=3$, then $n^{(0)}, \boldsymbol{x}^{(0)}=3,(3,3,3)$. Otherwise, $n^{(0)}=2^{k} \cdot z-3 k, x_{1}^{(0)}=\cdots=x_{k}^{(0)}=2$.

(c) $n^{(i)}>n^{(i-1)}$ for $i=1, \cdots, t$.

(d) $n^{(t)}, \boldsymbol{x}^{(t)}=n, \boldsymbol{x}$.

The proof is in the next section. Below we give some immediate corollaries of the theorem, using the same notation.

COROLlaRY 1. $k$ must satisfy $2^{k}-3 k \leqq n . \quad$ [By (b), since $z \geqq 1$.]

COROLlary 2. $z$ must satisfy $z \leqq(n+3) / 2 . \quad$ [By $(b)$, since $k \geqq 1$.

Corollary 3. The only fundamental solution to Equation (1) with $z \geqq n$ is the trivial solution.

4. In this section, we prove Theorem 1. First we state and prove some simple lemmas.

Lemma 1. Let $n, z, \boldsymbol{x}$ be a SOL.

If $z=3$, then $\chi(x) \geqq 2$.

If $z \leqq 2$, then $\chi(x) \geqq 3$.

If $z=1$, and $\chi(x)=3$, then $x_{3} \geqq 3$.

Proof. If $z \leqq 3$ and $\chi(x)=1$, then by (3) $2 x_{1} \leqq 3$ which contradicts $x_{1}>1$. Hence $\chi(x) \geqq 2$. If $z \leqq 2$ and $\chi(x) \leqq 2$, then by (1) $x_{1}^{2}+x_{2}^{2}+(n-2) \cdot 1^{2} \leqq 2 \cdot x_{1} \cdot x_{2} \cdot 1$. Thus $\left(x_{1}-x_{2}\right)^{2} \leqq 2-n$. This contradicts (4). Finally suppose $z=1, \chi(x)=3$ and $x_{3}=2$. Then by (1) 
$x_{1}^{2}+x_{2}^{2}+(n+1)=2 x_{1} x_{2}$, a contradiction.

LeMma 2. Let $n, z, x$ be a SOL with $k=\chi(x)$. When $z=1$ and $k=3, n^{(0)}, z, \boldsymbol{x}^{(0)}=3,1,(3,3,3)$ is a SOL. Otherwise if $n^{(0)}=z \cdot 2^{k}-$ $3 k$ and $x_{1}^{(0)}=\cdots=x_{k}^{(0)}=2, x_{i}^{(0)}=1$ for $i=k+1, \cdots, n^{(0)}$, then $n^{(0)}$, $z, x$ is a SOL with $\chi\left(x^{(0)}\right)=k$.

Proof. Obviously $n^{(0)}, z, \boldsymbol{x}^{(0)}=1,3,(3,3,3)$ is a SOL. As for the other cases: $\sum x_{i}^{2}=4 k+n^{(0)}-k$ while $z \Pi x_{i}=z \cdot 2^{k}$, thus the definition of $n^{(0)}$ guarantees (1). (2) and (4) are trivial while to verify (3) we must check that

$$
4 \leqq z \prod_{i>1} x_{i}
$$

which is obvious when $z \geqq 4$ and true for $z \leqq 3$ by the constraints imposed by Lemma 1.

Lemma 3. Let $n, z, \boldsymbol{x}$ and $N, z, \boldsymbol{X}$ be two SOLs such that

(a) $\chi(x)=\chi(X)=k$

(b) $X_{1}>x_{1}$

(c) $X_{j} \geqq x_{j}$ for $j=2, \cdots, k$.

Let $r$ be the last index $j$ for which $X_{j}>x_{j}$. Let $s^{\prime}$ be the first index $j$ for which $x_{j}<x_{1}$, and define $s=s^{\prime}$ if $s^{\prime} \leqq r, s=1$ if $s^{\prime}>r$. Then $m, z, w$ is a SOL if

$$
\begin{aligned}
& m=n-2 x_{s}-1+z \prod_{i \neq s} x_{i} \\
& w_{i}=x_{i} \text { for } i \leqq k, i \neq s \\
& w_{s}=x_{s}+1 \\
& w_{i}=1 \text { for } i>k .
\end{aligned}
$$

Moreover $m>n$.

Proof. We use the notation $\sum$ and $\Pi$ to denote sums and products for which the index $i$ runs from 1 to $k$, and append a prime to mean that $i \neq s$.

To check that $w$ really is a SOL we must check (1) and (3). Now by (1) $\sum x_{i}^{2}=z \Pi x_{i}-(n-k)$. Thus $\sum w_{i}^{2}=z \Pi w_{i}=z \Pi^{\prime} x_{i}-(n-$ k) $+2 x_{s}+1$. So by the definition of $m$, (1) is satisfied.

If $s>1$, then since $\boldsymbol{x}$ satisfies (3) so will $\boldsymbol{w}$. We may therefore assume $s=1$. By the definition of $s, x_{1}=\cdots=x_{r}$ and $x_{r+1}=X_{r+1}, \cdots$, $x_{k}=X_{k}$. Thus either (i) $r=1$ or (ii) $r \geqq 2$ and $x_{1}=x_{2}$. In case (i) we note that $N, z, X$ satisfies (3), that $z \Pi^{\prime} w_{i}=z \Pi^{\prime} X_{i}$, and that $X_{1}>x_{1}$ implies $2 X_{1} \geqq 2\left(x_{1}+1\right)=2 w_{1}$. Thus $\boldsymbol{w}$ satisfies (3). In case (ii) we must check that $z \Pi^{\prime} x_{i} \leqq 2 x_{1}+2$. Dividing by $x_{1}=x_{2}$ and 
recalling that $x_{1} \geqq 2$ we see that it suffices to know that

$$
z \prod_{i=3}^{k} x_{i} \geqq 3 \text {. (The empty product equals } 1 \text {.) }
$$

This is certainly true if $z \geqq 3$ and easily checked via the constraints of Lemma 1 when $z<3$.

Finally we note that $m>n$ is equivalent to $z \Pi^{\prime} x_{i} \geqq 2\left(x_{s}+1\right)$. Multiplying by $x_{s}$ we see that it suffices to show $z \prod x_{i} \geqq 2\left(x_{s}^{2}+x_{s}\right)$ and since $x_{1} \geqq x_{s}$ it suffices to prove this when $s=1$. Dividing by $x_{1}$ we obtain Equation (3) for $\boldsymbol{w}$, which was verified above.

Proof of Theorem 1. The $n^{(0)}, z, \boldsymbol{x}^{(0)}$ defined in (b) is a SOL by Lemma 2. If $\left(x_{1}, \cdots, x_{k}\right) \neq\left(x_{1}^{(0)}, \cdots, x_{k}^{(0)}\right)$, we apply Lemma 3 (with $s=1)$ to obtain a SOL $n^{(1)}, z, \boldsymbol{x}^{(1)}$, with $n^{(1)}>n^{(0)}$. By induction: At step $i$, if $r>1$, we will have either $x_{1}^{(i)}=\cdots=x_{s-1}^{(i)}>x_{s}^{(i)}=\cdots=x_{r}^{(i)}$ where $x_{s-1}^{(i)}=x_{s}^{(i)}+1$, or $x_{1}^{(i)}=x_{r}^{(i)}$ and $s=1$. Hence we will be able to apply Lemma 3 . When $r=1$, at $i=t$ say, we have $\left(x_{1}, \cdots, x_{k}\right)=$ $\left(x_{1}^{(t)}, \cdots, x_{k}^{(t)}\right)$ and by (1) both $n$ and $n^{(t)}$ equal

$$
k+z \prod_{i=1}^{k} x_{i}-\sum_{i=1}^{k} x_{i}^{2}
$$

Hence, $n^{(t)}, z, \boldsymbol{x}^{(t)}=n, z, x$.

5. The following corollary is an easy consequence of the proof of Theorem 1.

Corollary 4. Every SOL $n, z, \boldsymbol{x}$ satisfies $n \geqq x_{1}$.

Proof. (We use the notation of Theorem 1.) To construct $\boldsymbol{x}^{(i+1)}$ from $\boldsymbol{x}^{(i)}$ we applied Lemma 3 . Thus for $1 \leqq j \leqq k$

$$
x_{j}^{(i+1)}-x_{j}^{(i)}=\left\{\begin{array}{l}
0 \text { if } j \neq s \\
1 \text { if } j=s .
\end{array}\right.
$$

Since $n^{(i+1)}>n^{(i)}$,

$$
\sum_{j=1}^{k} x_{j}^{(i+1)}-x_{j}^{(i)} \leqq n^{(i+1)}-n^{(i)} .
$$

Summing these equations for $i=v, \cdots, t$ we get

$$
n^{(t)}=n \geqq n^{(v)}+\sum_{j=1}^{k} x_{j}-x_{j}^{(v)} \geqq n^{(v)}+x_{1}-x_{1}^{(v)} .
$$

If $z \neq 1$ or $\chi(x) \neq 3$, then $x_{1}^{(0)}=2$ and $n^{(0)} \geqq 4$. Thus by (5), $n \geqq x_{1}+2$. If $z=1$ and $\chi(\boldsymbol{x})=3$, then $n^{(0)}, \boldsymbol{x}^{(0)}=3,(3,3,3) ; n^{(1)}$, $\boldsymbol{x}^{(1)}=5,(4,3,3,1,1)$; and $n^{(2)}, \boldsymbol{x}^{(2)}=10,(4,4,3,1, \cdots, 1)$. Thus the 
corollary is true for $x=\boldsymbol{x}^{(0)}$ or $\boldsymbol{x}^{(1)}$. Setting $v=2$ in (5), we have $n \geqq x_{1}+6$ otherwise.

6. Lemma 3 and Theorem 1 yield an algorithm that produces only SOLs, and each only once.

THEOREM 2. The following seven step algorithm constructs all SOLs $n, z, \boldsymbol{x}$ with $n \leqq M$.

Let $A$ be a list of SOLs, initially empty. The set of SOLs put into $A$ will be the SOLs sought.

(1) Set $k=1$ and $z=4$.

(2) Using the current values of $z$ and $k$, put the SOL constructed in Lemma 2 on the bottom of the list $A$.

(3) If $A$ is empty, go to Step 6, otherwise remove the top SOL $n, z, \boldsymbol{x}$ from $A$.

(4) Define $w_{1}=x_{1}+1, w_{i}=x_{i}$ for $i \geqq 2, k=\chi(\boldsymbol{x})$ and

$$
\nu=z \prod_{i=2}^{k} w_{i}-2 w_{1}+1 \text {. }
$$

Let $m=n+\nu$. If $n<m<M$ define $w_{i}=1$ for $i=n+1, \cdots, m$. $m, z, w$ is a new SOL. Put it on the bottom of $A$. (If $m$ is not between $n$ and $M$ we do nothing.)

(5) Find the smallest index $s \leqq k$ satisfying $x_{1}-x_{s}=1$. If no such $s$ exists, go to Step 3 ; otherwise define $w_{s}=x_{s}+1, w_{i}=x_{i}$ for $i \neq s, k=\chi(x)$ and

$$
\nu=z \prod_{i \neq s}^{k} w_{i}-2 w_{s}+1
$$

Let $m=n+\nu$. If $m>M$ go to Step 3. If $m \leqq M$ define $w_{i}=$ 1 for $i=n+1, \cdots, m$. $m, z, w$ is a new SOL (since $n<m$ is always true). Put it on the bottom of $A$ and go to Step 3.

(6) Increase $z$ by 1 and set $\nu=z \cdot 2^{k}-3 k$. If $\nu \leqq M$ go to Step 3, otherwise go to Step 7.

( 7 ) Increase $k$ by 1 . If $k=2$, set $z=3$, otherwise set $z=1$. Set $\nu=z \cdot 2^{k}-3 k$. If $\nu \leqq M$ go to Step 2, otherwise stop.

Proof. Every SOL $n, z, \boldsymbol{x}$ satisfying $n \leqq M$ eventually is put on $A$ because the algorithm produces a unique sequence of SOLs passing through the $\chi(\boldsymbol{x})=k$ SOLs of the form $m, z, \boldsymbol{w}^{(j)}$ where $\chi\left(\boldsymbol{w}^{(j)}\right)=k$ and

$$
\boldsymbol{w}^{(j)}=\left(x_{j}, \cdots, x_{j}, x_{j+1}, x_{j+2}, \cdots, x_{k}, 1, \cdots, 1\right) .
$$

(Uniqueness is guaranteed by Step 5.)

Theorem 2 is extremely powerful, and it is no trouble to produce 
a table of SOLs by hand for moderately large $n$. The Appendix lists all solutions of (1)-(4) with $n \leqq 45$ except the trivial solution (when $z=n)$. We have omitted those $x_{i}$ which equal 1 .

7. In this section, we will apply Theorem 2 to get a better bound on $z$ than that given by Corollary 2 .

Suppose $n, z, \boldsymbol{x}$ is a SOL with $k=\chi(\boldsymbol{x})$, and suppose $n \neq 2 z-3$. In particular, if $k=1$, then $n \neq n^{(0)}$. Hence either (i) $k \geqq 2$ or (ii) $k=1$ and $n \geqq n^{(1)}$. In case (i) by Theorem 1 (b)

$$
z \leqq(n+3 k) / 2^{k} \leqq(n+6) / 4 \text {. }
$$

In case (ii) since $n^{(0)}=2 z-3$ and $n^{(1)}=n^{(0)}+z-5$, we see that $z \leqq(n+8) / 3$. Now if $n \geqq 14,(n+8) / 3 \leqq(n+6) / 4$, while for $n \leqq$ $14, z \leqq(n+8) / 3$ by inspection.

THEOREM 3. The only SOLs $n, z, \boldsymbol{x}$ with $z>(n+8) / 3$ are the SOLs with $n$ odd, $z=(n+3) / 2, \boldsymbol{x}=(2,1, \cdots, 1)$.

Proof. Since $n$ even implies $n \neq 2 z-3$, there are no SOLs with $z>(n+8) / 3$. If $n$ is odd and $n=2 z-3$, then $\chi(x)=1$ and $n=$ $n^{(0)}, \boldsymbol{x}=\boldsymbol{x}^{(0)}$ of Theorem 1 (b).

Theorem 3 is hardly the best possible. For any $n$, each SOL $n, z, \boldsymbol{x}$ is the end point of one of the chains described in Theorem 1 , and in general, the longer the chain, the larger $n$ must be compared to $z$. So for example if $n \geqq n^{(2)}, z \leqq(n+15) / 4$ when $\chi(x)=1$ and if $\chi(\boldsymbol{x}) \geqq 2$ and $z \geqq 3$, then $z \leqq(n+10) / 8$. Thus there are no solutions to (1) when $(n+8) / 3>z>(n+15) / 4$, etc. .

8. Hurwitz asked if there exists $n$ for which the only solutions to (1) have $z=n$. There are.

Proposition. There are 15 values of $n \leqq 301020$ for which (1)(4) has no nontrivial solutions. They occur when $n=12,24,32,48$, $60,108,240,384,480,608,972,984,1020$, and 2688.

This is the result of a computer program implementing Theorem 2. Suppose a computer has $b$ binary bits per word. Since one only wants to remember which $n$ have at least one SOL, this information can be stored in a single bit. Hence at most $[n / b]+1$ words are needed to keep track of which $n$ have a SOL. Suppose $\chi(x)=k \geqq$ 17 , then $2^{k}-3 k \geqq 301,021$. Thus all SOLs for which $n \leqq 301,020$ have $k \leqq 16$. By Theorem $3, z<2^{16}$. It is possible to show that for $n \geqq 55, x_{1}<\sqrt{2 n}$. Hence $x_{1}<2^{9}$. Thus, if $b \geqq 25, n, z$, and $k$ can be 
packed into one computer word, and $x_{1}, \cdots, x_{k}$ can be packed $[b / 8]$ to a computer word. So e.g., if $b=25$, no more than six computer words are needed for the $x_{i}$. The list $A$ of active solutions will not grow too large if the solutions are packed in this way. Finally let me comment that removing SOLs from the end of $A$, rather than the beginning (see Step 3) will save considerable computing time, since the stack $A$ need not be "pushed down" after a SOL is removed. Moreover, if the last entry for each SOL is the word containing ( $n$, $z, k)$, then upon removing the last word of $A$ one knows how many words were needed to store $x_{1}, \cdots, x_{k}$.

It is tempting to conjecture that there is at least one SOL for all $n>2688$.

Proposition. There are nontrivial solutions to (1) whenever $n \equiv$ $1 \bmod u$ and $n>u^{2}$, or $n \equiv 2 \bmod u^{2}$ for any integer $u>1$.

Proof. If $n, z, \boldsymbol{x}$ is a SOL with $\chi(\boldsymbol{x})=k$, then so is $n^{\prime}=n+$ $d \Pi x_{i}, z^{\prime}=z+d, \boldsymbol{x}^{\prime}=\left(x_{1}, \cdots, x_{k}, 1, \cdots, 1\right)$ for any $d \geqq 0$. Apply this fact to the SOLs, $n=u^{2}+2, z=3, z=2 u, x=(u, 1, \cdots, 1)$ and the SOLs, $n=u^{2}+2, z=3, \boldsymbol{x}=(u, u, 1, \cdots, 1)$.

COROLLARY. If (1) has only trivial solutions, then $n \equiv 0$ or $8 \bmod 12$.

[Set $u=2,3$.

I take this opportunity to thank Ed Bender for many valuable discussions. 


\section{APPENDIX}

(See the end of Section 6.)

\begin{tabular}{|c|c|c|c|c|c|c|c|c|c|c|c|c|c|}
\hline $\mathrm{N}$ & $\mathrm{Z}$ & $\mathrm{X} 1$ & $\mathrm{X} 2$ & $\mathrm{X} 3$ & $\mathrm{X} 4$ & $\mathrm{X} 5$ & $\mathrm{~N}$ & $\mathrm{Z}$ & $\mathrm{X} 1$ & $\mathrm{X} 2$ & $\mathrm{X} 3$ & $\mathrm{X} 4$ & $\mathrm{X} 5$ \\
\hline 3 & 1 & 3 & 3 & 3 & & & 22 & 2 & 4 & 3 & 2 & & \\
\hline 4 & 1 & 2 & 2 & 2 & 2 & & & 3 & 3 & 2 & 2 & & \\
\hline \multirow[t]{2}{*}{5} & 1 & 4 & 3 & 3 & & & & 3 & 6 & 4 & & & \\
\hline & 4 & 2 & & & & & & 5 & 4 & 2 & & & \\
\hline 6 & 3 & 2 & 2 & & & & & 7 & 2 & 2 & & & \\
\hline \multirow[t]{4}{*}{7} & 1 & 3 & 2 & 2 & 2 & & & 10 & 3 & & & & \\
\hline & 2 & 2 & 2 & 2 & & & 23 & 1 & 6 & 3 & 2 & 2 & \\
\hline & 3 & 3 & 2 & & & & & 1 & 6 & 5 & 3 & & \\
\hline & 5 & 2 & & & & & & 4 & 2 & 2 & 2 & & \\
\hline 8 & 1 & 4 & 2 & 2 & 2 & & & 5 & 5 & 2 & & & \\
\hline 9 & 6 & 2 & & & & & & 13 & 2 & & & & \\
\hline \multirow[t]{4}{*}{10} & 1 & 4 & 4 & 3 & & & 24 & & NONE & & & & \\
\hline & 2 & 3 & 2 & 2 & & & 25 & 1 & 7 & 5 & 3 & & \\
\hline & 4 & 2 & 2 & & & & & 2 & 5 & 3 & 2 & & \\
\hline & 6 & 3 & & & & & & 4 & 4 & 3 & & & \\
\hline \multirow[t]{3}{*}{11} & 2 & 4 & 2 & 2 & & & & 6 & 3 & 2 & & & \\
\hline & 3 & 3 & 3 & & & & & 10 & 4 & & & & \\
\hline & 7 & 2 & & & & & & 11 & 3 & & & & \\
\hline 12 & & NONE & & & & & & 14 & 2 & & & & \\
\hline \multirow[t]{5}{*}{13} & 1 & 5 & 4 & 3 & & & 26 & 1 & 5 & 4 & 4 & & \\
\hline & 3 & 4 & 3 & & & & & 2 & 6 & 3 & 2 & & \\
\hline & 4 & 3 & 2 & & & & & 8 & 2 & 2 & & & \\
\hline & 7 & 3 & & & & & & 10 & 5 & & & & \\
\hline & 8 & 2 & & & & & 27 & 1 & 3 & 3 & 3 & 2 & \\
\hline \multirow[t]{4}{*}{14} & 1 & 3 & 3 & 2 & 2 & & & 3 & 4 & 2 & 2 & & \\
\hline & 1 & 6 & 4 & 3 & & & & 3 & 5 & 5 & & & \\
\hline & 4 & 4 & 2 & & & & & 15 & 2 & & & & \\
\hline & 5 & 2 & 2 & & & & 28 & 1 & 3 & 2 & 2 & 2 & 2 \\
\hline \multirow[t]{2}{*}{15} & 3 & 2 & 2 & 2 & & & & 1 & 4 & 4 & 2 & 2 & \\
\hline & 9 & 2 & & & & & & 4 & 5 & 3 & & & \\
\hline 16 & 8 & 3 & & & & & & 12 & 3 & & & & \\
\hline \multirow[t]{4}{*}{17} & 1 & 2 & 2 & 2 & 2 & 2 & 29 & 4 & 6 & 3 & & & \\
\hline & 2 & 3 & 3 & 2 & & & & 5 & 3 & 3 & & & \\
\hline & 8 & 4 & & & & & & 11 & 4 & & & & \\
\hline & 10 & 2 & & & & & & 16 & 2 & & & & \\
\hline \multirow[t]{2}{*}{18} & 3 & 4 & 4 & & & & 30 & 1 & 6 & 6 & 3 & & \\
\hline & 6 & 2 & 2 & & & & & 2 & 3 & 3 & 3 & & \\
\hline \multirow[t]{6}{*}{19} & 1 & 4 & 3 & 2 & 2 & & & 3 & 5 & 2 & 2 & & \\
\hline & 1 & 5 & 5 & 3 & & & & 6 & 4 & 2 & & & \\
\hline & 1 & 4 & 4 & 4 & & & & 9 & 2 & 2 & & & \\
\hline & 5 & 3 & 2 & & & & 31 & 1 & 6 & 4 & 4 & & \\
\hline & 9 & 3 & & & & & & 2 & 3 & 2 & 2 & 2 & \\
\hline & 11 & 2 & & & & & & 2 & 4 & 4 & 2 & & \\
\hline \multirow[t]{2}{*}{20} & 2 & 2 & 2 & 2 & 2 & & & 3 & 6 & 2 & 2 & & \\
\hline & 4 & 3 & 3 & & & & & 3 & 6 & 5 & & & \\
\hline \multirow[t]{3}{*}{21} & 3 & 5 & 4 & & & & & 5 & 2 & 2 & 2 & & \\
\hline & 9 & 4 & & & & & & 7 & 3 & 2 & & & \\
\hline & 12 & 2 & & & & & & 11 & 5 & & & & \\
\hline 22 & 1 & 5 & 3 & 2 & 2 & & & 13 & 3 & & & & \\
\hline
\end{tabular}




\begin{tabular}{|c|c|c|c|c|c|c|c|c|c|c|c|c|c|}
\hline $\mathrm{N}$ & $\mathrm{Z}$ & $\mathrm{X} 1$ & $\mathrm{X} 2$ & $\mathrm{X} 3$ & $\mathrm{X} 4$ & $\mathrm{X} 5$ & $\mathrm{~N}$ & $\mathrm{Z}$ & $\mathrm{X} 1$ & $\mathrm{X} 2$ & $\mathrm{X} 3$ & $\mathrm{X} 4$ & $\mathrm{X} 5$ \\
\hline & 17 & 2 & & & & & 38 & 6 & 3 & 3 & & & \\
\hline 32 & & NON & & & & & & 7 & 4 & 2 & & & \\
\hline \multirow[t]{4}{*}{33} & 3 & 7 & 5 & & & & & 11 & 2 & 2 & & & \\
\hline & 6 & 5 & 2 & & & & 39 & 1 & 9 & 6 & 3 & & \\
\hline & 12 & 4 & & & & & & 6 & 2 & 2 & 2 & & \\
\hline & 18 & 2 & & & & & & 21 & 2 & & & & \\
\hline \multirow[t]{6}{*}{34} & 1 & 7 & 4 & 4 & & & 40 & 1 & 6 & 4 & 2 & 2 & \\
\hline & 4 & 3 & 2 & 2 & & & & 2 & 4 & 2 & 2 & 2 & \\
\hline & 4 & 4 & 4 & & & & & 16 & 3 & & & & \\
\hline & 6 & 6 & 2 & & & & 41 & 2 & 4 & 3 & 3 & & \\
\hline & 10 & 2 & 2 & & & & & 4 & 5 & 4 & & & \\
\hline & 14 & 3 & & & & & & 13 & 5 & & & & \\
\hline \multirow[t]{5}{*}{35} & 1 & 5 & 4 & 2 & 2 & & & 14 & 4 & & & & \\
\hline & 1 & 8 & 4 & 4 & & & & 22 & 2 & & & & \\
\hline & 1 & 7 & 6 & 3 & & & 42 & 12 & 2 & 2 & & & \\
\hline & 3 & 3 & 3 & 2 & & & 43 & 1 & 7 & 4 & 2 & 2 & \\
\hline & 19 & 2 & & & & & & 1 & 7 & 7 & 3 & & \\
\hline \multirow[t]{2}{*}{36} & 3 & 2 & 2 & 2 & 2 & & & 2 & 6 & 4 & 2 & & \\
\hline & 12 & 5 & & & & & & 3 & 7 & 6 & & & \\
\hline \multirow[t]{8}{*}{37} & 1 & 4 & 2 & 2 & 2 & 2 & & 4 & 4 & 2 & 2 & & \\
\hline & 1 & 5 & 5 & 4 & & & & 5 & 5 & 3 & & & \\
\hline & 5 & 4 & 3 & & & & & 7 & 5 & 2 & & & \\
\hline & 8 & 3 & 2 & & & & & 9 & 3 & 2 & & & \\
\hline & 12 & 6 & & & & & & 13 & 6 & & & & \\
\hline & 13 & 4 & & & & & & 17 & 3 & & & & \\
\hline & 15 & 3 & & & & & & 23 & 2 & & & & \\
\hline & 20 & 2 & & & & & 44 & 1 & 5 & 2 & 2 & 2 & 2 \\
\hline \multirow[t]{4}{*}{38} & 1 & 4 & 3 & 3 & 2 & & & 1 & 8 & 4 & 2 & 2 & \\
\hline & 1 & 8 & 6 & 3 & & & 45 & 15 & 4 & & & & \\
\hline & 2 & 5 & 4 & 2 & & & & 24 & 2 & & & & \\
\hline & 3 & 6 & 6 & & & & & & & & & & \\
\hline
\end{tabular}

\section{REFERENCE}

1. A. Hurwitz, Über eine Aufgabe der unbestimmten Analysis, Archiv. der Math. und Phys., III Reine, Bd 11 (1907), 185-196.

Received October 11, 1972.

Institute For Defense ANALyses 



\section{PACIFIC JOURNAL OF MATHEMATICS}

\section{EDITORS}

RICHARD ARENS (Managing Editor)

University of California

Los Angeles, California 90024

\section{R. A. Beaumont \\ University of Washington \\ Seattle, Washington 98105}

\section{J. DugundjI*}

Department of Mathematics University of Southern California Los Angeles, California 90007

D. Gilbarg and J. Milgram

Stanford University

Stanford, California 94305

\section{ASSOCIATE EDITORS}
E. F. BeCKenBaCH
B. H. NeumanN
F. WOLF
K. YoSHIDA

\section{SUPPORTING INSTITUTIONS}

\author{
UNIVERSITY OF BRITISH COLUMBIA \\ CALIFORNIA INSTITUTE OF TECHNOLOGY \\ UNIVERSITY OF CALIFORNIA \\ MONTANA STATE UNIVERSITY \\ UNIVERSITY OF NEVADA \\ NEW MEXICO STATE UNIVERSITY \\ OREGON STATE UNIVERSITY \\ UNIVERSITY OF OREGON \\ OSAKA UNIVERSITY
}

\author{
UNIVERSITY OF SOUTHERN CALIFORNIA \\ STANFORD UNIVERSITY \\ UNIVERSITY OF TOKYO \\ UNIVERSITY OF UTAH \\ WASHINGTON STATE UNIVERSITY \\ UNIVERSITY OF WASHINGTON

$* * *$
$*$
AMERICAN MATHEMATICAL SOCIETY
NAVAL WEAPONS CENTER

The Supporting Institutions listed above contribute to the cost of publication of this Journal, but they are not owners or publishers and have no responsibility for its content or policies.

Mathematical papers intended for publication in the Pacific Journal of Mathematics should be in typed form or offset-reproduced, (not dittoed), double spaced with large margins. Underline Greek letters in red, German in green, and script in blue. The first paragraph or two must be capable of being used separately as a synopsis of the entire paper. Items of the bibliography should not be cited there unless absolutely necessary, in which case they must be identified by author and Journal, rather than by item number. Manuscripts, in duplicate if possible, may be sent to any one of the four editors. Please classify according to the scheme of Math. Rev. Index to Vol. 39. All other communications to the editors should be addressed to the managing editor, or Elaine Barth, University of California, Los Angeles, California, 90024.

100 reprints are provided free for each article, only if page charges have been substantially paid. Additional copies may be obtained at cost in multiples of 50 .

The Pacific Journal of Mathematics is issued monthly as of January 1966. Regular subscription rate: $\$ 60.00$ a year (6 Vols., 12 issues). Special rate: $\$ 30.00$ a year to individual members of supporting institutions.

Subscriptions, orders for back numbers, and changes of address should be sent to Pacific Journal of Mathematics, 103 Highland Boulevard, Berkeley, California, 94708.

PUBLISHED BY PACIFIC JOURNAL OF MATHEMATICS, A NON-PROFIT CORPORATION

Printed at Kokusai Bunken Insatsusha (International Academic Printing Co., Ltd.), 270, 3-chome Totsuka-cho, Shinjuku-ku, Tokyo 160, Japan

* C. R. DePrima California Institute of Technology, Pasadena, CA 91109, will replace J. Dugundji until August 1974. 


\section{Pacific Journal of Mathematics}

Vol. 50, No. $2 \quad$ October, 1974

Mustafa Agah Akcoglu, John Philip Huneke and Hermann Rost, A counter example to the Blum Hanson theorem in general spaces .............

Huzihiro Araki, Some properties of modular conjugation operator of von

Neumann algebras and a non-commutative Radon-Nikodym theorem

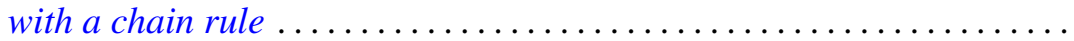

E. F. Beckenbach, Fook H. Eng and Richard Edward Tafel, Global properties of rational and logarithmico-rational minimal surfaces .....

David W. Boyd, A new class of infinite sphere packings ............. 383

K. G. Choo, Whitehead Groups of twisted free associative algebras ........

Charles Kam-Tai Chui and Milton N. Parnes, Limit sets of power series

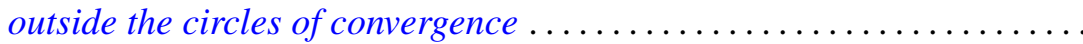

Allan Clark and John Harwood Ewing, The realization of polynomial

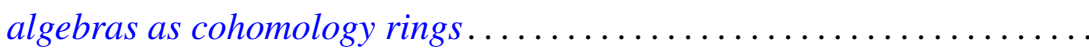

Dennis Garbanati, Classes of circulants over the p-adic and rational

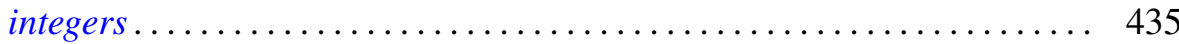

Arjun K. Gupta, On a "square" functional equation ................... 449

David James Hallenbeck and Thomas Harold MacGregor, Subordination and extreme-point theory ............................. 455

Douglas Harris, The local compactness of $v X \ldots \ldots . . . . . . . . . . . .4469$

William Emery Haver, Monotone mappings of a two-disk onto itself which fix the disk's boundary can be canonically approximated by homeomorphisms .................................. 477

Norman Peter Herzberg, On a problem of Hurwitz .................. 485

Chin-Shui Hsu, A class of Abelian groups closed under direct limits and subgroups formation ............................... 495

Bjarni Jónsson and Thomas Paul Whaley, Congruence relations and multiplicity types of algebras.....................

Lowell Duane Loveland, Vertically countable spheres and their wild sets.

Nimrod Megiddo, Kernels of compound games with simple components ....

Russell L. Merris, An identity for matrix functions ........ . .

E. O. Milton, Fourier transforms of odd and even tempered distributions ...

Dix Hayes Pettey, One-one-mappings onto locally connected generalized continua

Mark Bernard Ramras, Orders with finite global dimension

Doron Ravdin, Various types of local homogeneity. .

George Michael Reed, On metrizability of complete Moore spaces ...

Charles Small, Normal bases for quadratic extensions ..

Philip C. Tonne, Polynomials and Hausdorff matrices.... . . 